\title{
Aqueous Solution and Computed Gas Phase Properties of Meclofenamic Acid Sodium Salt
}

\author{
Sanjeevan J. Kharat \\ Chemistry Department, RNC Arts, JDB Commerce, and NSC Science College, \\ Nashik Road, Nashik, India \\ E-mail address: ksanjeevan@dataone.in , assoprof_kharatsj@rediffmail.com
}

\begin{abstract}
Paper reports densities, ultrasonic velocities, and refractive indices of aqueous solutions of meclofenamic acid sodium salt (Na-MCF). Densities, ultrasonic velocities, and refractive indices have been measured at $(298.15,303.15,308.15$, and 313.15$) \mathrm{K}$ and at atmospheric pressure. Limiting molar volume and limiting molar isentropic compressibility have been calculated. DFT method has been used for computation of dipole moment, free energy, hydration free energy, and HOMO and LUMO energies of Na-MCF. Gas phase properties have been computed by the use of G09 W Software.
\end{abstract}

Keywords: Density; ultrasonic velocity; refractive index; DFT; dipole moment; HOMO and LUMO energies hydration free energy; sodium meclofenamate

\section{INTRODUCTION}

Non-Steroidal Anti-Inflammatory Drugs (NSAIDS) are commonly used as pain relief medicines. They reduce pain or inflammation caused by headache, toothache, back pain, arthritis, menstrual cramps or major injury.

The most commonly used NSAIDS include sodium salicylate, sodium ibuprofen, sodium naproxen, and Na-MCF. The information regarding Drug-Water interactions is very important to understand the biochemical reactions.

Density and ultrasonic velocity data can be used to understand nature of drug-water (solute-solvent) interactions. In previous publications [1-2] density and ultrasonic velocity studies of aqueous solutions of sodium salicylate and sodium ibuprofen have reported. This paper reports densities, ultrasonic velocities, and refractive indices at $(298.15,303.15,308.15$, and 313.15$) \mathrm{K}$ of aqueous solutions of Na-MCF.

The molality range $0.1144 \leq \mathrm{m} \geq 0.3305 \mathrm{~mol} \cdot \mathrm{kg}^{-1}$ has been studied. This paper also reports hydration free energy and gas phase properties like dipole moment, free energy, and HOMO and LUMO energies of Na-MCF. 


\section{EXPERIMENTAL DETAILS}

Na-MCF (Sigma-Aldrich, Purity $\geq 98 \%$ ) was used without further purification. Solutions of Na-MCF were prepared in triply distilled deionized water by weight-by weight method in airtight stoppered glass bottle. Dhona balance to an accuracy of $\pm 1 \times 10^{-4} \mathrm{~g}$ was used to record the masses. Bi-capillary Pycnometer [3] was used for density measurements. At $2 \mathrm{MHz}$, ultrasonic velocity measurements [3] were made by the use of Ultrasonic Interferometer (M- 83 Mittal Enterprises, India). Bi-capillary Pycnometer and Ultrasonic Interferometer were calibrated with triply distilled water before the measurements of density and ultrasonic velocity, respectively of aqueous solutions. Uncertainties in the density and ultrasonic velocity measurements were $5.8 \cdot 10^{-2} \mathrm{~kg} \cdot \mathrm{m}^{-3}$ and $0.23 \mathrm{~m} \cdot \mathrm{s}^{-1}$, respectively. Refractive indices are measured by using Cyber Abbe refractometer. Accuracy in refractive index measurements was \pm 0.0002 .

All gas phase calculations were carried out by the use of Gaussian 09W software package. The geometry of Na-MCF was fully optimized and the frequencies were calculated in the gas phase by using DFT RB3LYP method at $6-31++\mathrm{G}(\mathrm{d}, \mathrm{p})$ basis set [4-5]. The optimized geometry was used to compute the hydration free energy of Na-MCF by using IEFPCM [6-7] solvation model.

\section{1. Limiting molar volume $\left(V_{\phi}^{0}\right)$}

The empirical equation [8-11] used for calculation of the limiting molar volume was

$$
V_{\phi}=V_{\phi}^{0}+V_{\mathrm{s}} m^{1 / 2}
$$

$V_{\phi}^{0}$ and $V_{\mathrm{s}}$ are partial molar volume and solute-solute interaction parameter. The apparent molar volumes $V_{\phi}$ were calculated by the use of the equation [11-12]

$$
V_{\phi}=(M / \rho)-\left[\left(\rho-\rho_{0}\right) / m \rho \rho_{0}\right] \ldots \ldots \ldots \ldots . . .2
$$

$M, \rho, \rho_{0}$ and, $m$ are the molar mass of the solute, density of the aqueous solution, density of the water, and molality of the Na-MCF aqueous solution. Density, apparent molar volume, and limiting molar volumes are reported in the Table 1.

Table 1. Densities $(\boldsymbol{\rho})$, apparent molar volumes $\left(V_{\phi}\right)$, partial molar volumes $\left(V_{\phi}^{0}\right)$, and refractive indices $(n)$ of Na-MCF in Water

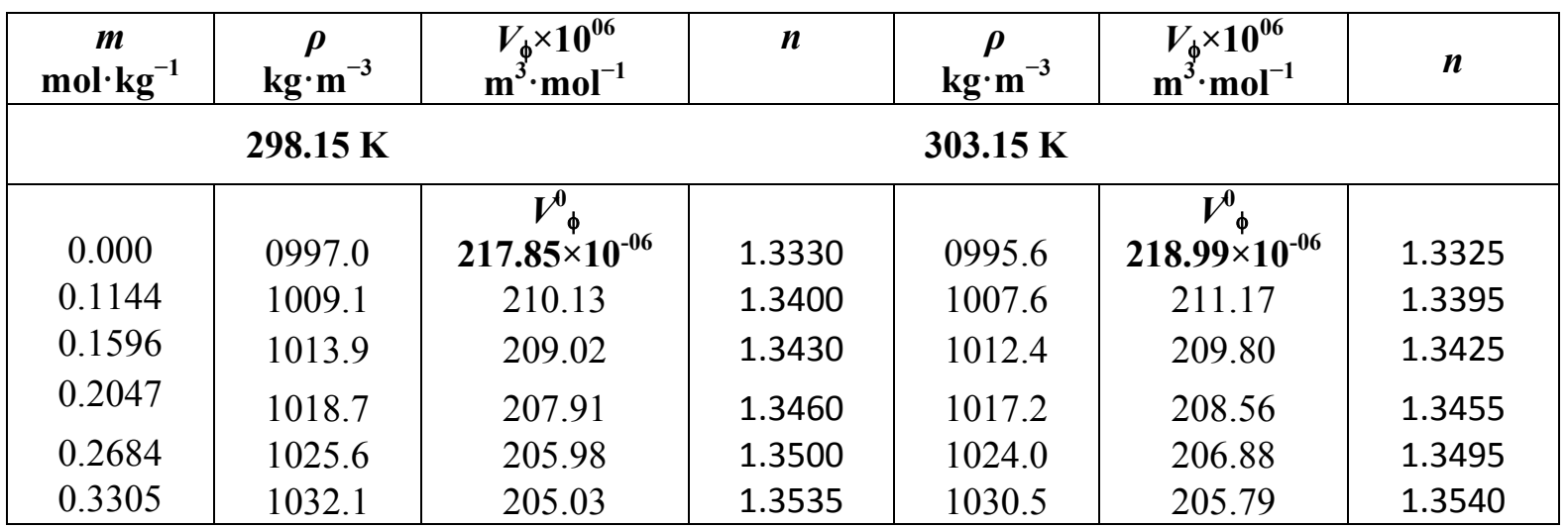




\begin{tabular}{|c|c|c|c|c|c|c|}
\hline \multicolumn{2}{|r|}{$308.15 \mathrm{~K}$} & \multicolumn{5}{|c|}{$313.15 \mathrm{~K}$} \\
\hline 0.0000 & 0994.0 & $\begin{array}{c}V_{\phi}^{0} \\
221.87 \times 10^{-06}\end{array}$ & 1.3320 & 0992.2 & $\begin{array}{c}V_{\phi}^{0} \\
223.12 \times 10^{-06}\end{array}$ & 1.3315 \\
\hline 0.1144 & 1006.1 & 213.98 & 1.3390 & 1003.8 & 215.12 & 1.3385 \\
\hline 0.1596 & 1010.8 & 212.50 & 1.3420 & 1008.5 & 213.38 & 1.3415 \\
\hline 0.2047 & 1015.5 & 211.20 & 1.3450 & 1013.2 & 211.94 & 1.3445 \\
\hline 0.2684 & 1022.1 & 209.71 & 1.3490 & 1019.7 & 210.71 & 1.3485 \\
\hline 0.3305 & 1028.5 & 208.43 & 1.3535 & 1026.1 & 209.29 & 1.3525 \\
\hline
\end{tabular}

Density varies linearly with molality of the aqueous solutions of Na-MCF. Variations of density with molality at different temperatures are shown in the Figure 1 . The observed values of $V_{\phi}^{0}$ and $V_{\mathrm{s}}$ at $298.15,303.15,308.15$, and 313.15$) \mathrm{K}$ are $(217.85,218.99,221.87$, and $223.12) \times 10^{-6}$ and $(-2.24,2.31,2.34,2.42) \times 10^{-5}$, respectively. Least squares method was used to calculate $V_{\phi}^{0}$ and $V_{\mathrm{s}}$ values. The thermodynamic property $V_{\phi}^{0}$ is useful to get the information about solute-solvent and solute-solute interactions. The positive value of $V_{\phi}^{0}$ is the indication of strong solute-solvent (Na-MCF-Water) interactions. Negative values of $V_{\mathrm{s}}$ suggest weak solute-solute (Na-MCF - Na-MCF) interaction.

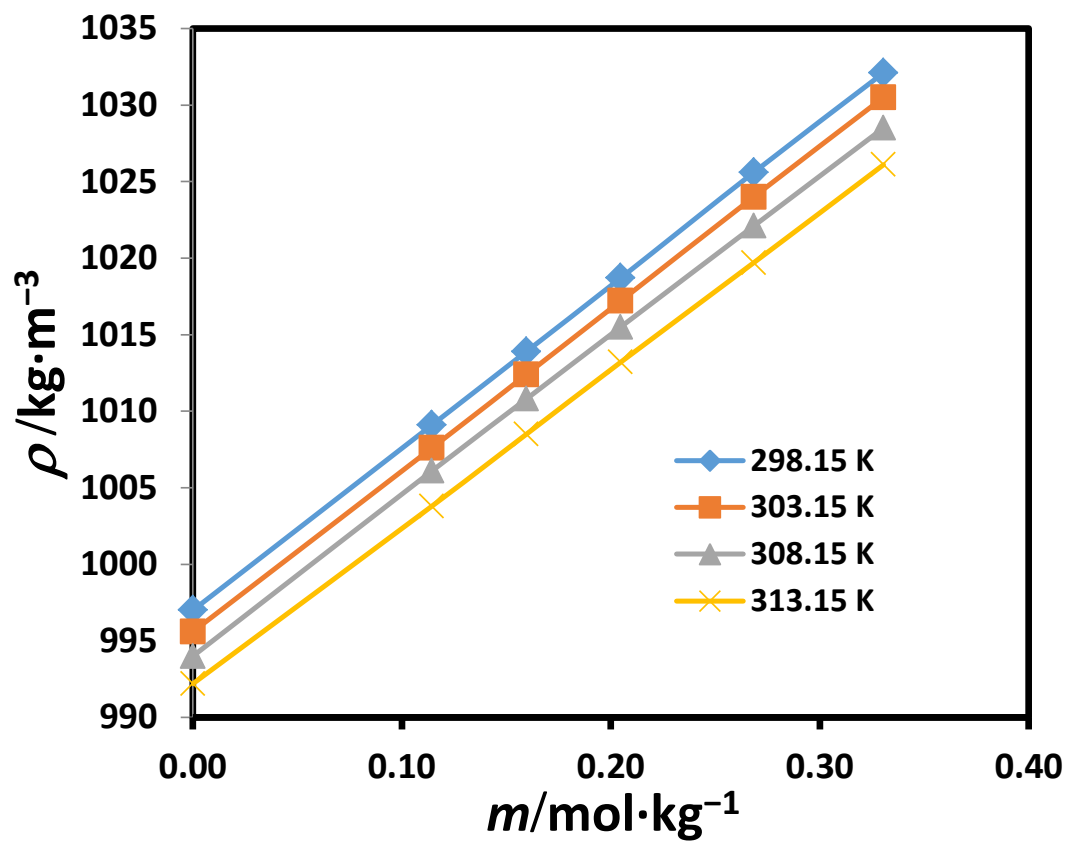

Figure 1. Variation of density of aqueous solutions of Na-MCF with molality.

\section{2. Limiting molar isentropic compressibility $\left(K_{\phi, \mathrm{S}}^{\mathbf{0}}\right)$}

Ultrasonic velocities of aqueous solutions of Na-MCF are reported in Table 2. Ultrasonic velocity of Na-MCF aqueous solutions increases with increase in molality and temperature. Figure 2 depicts the variation of ultrasonic velocity with molality at different temperatures. By the use of ultrasonic velocity values, isentropic compressibility [13] values were calculated with help of following equation. 


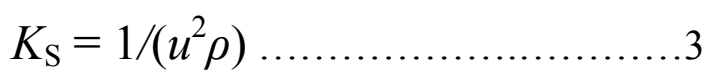

$K_{\mathrm{S}}, u$, and, $\rho$ are the isentropic compressibility $\left(\mathrm{Pa}^{-1}\right)$, ultrasonic velocity $\left(\mathrm{m} \cdot \mathrm{s}^{-1}\right)$, and density $\left(\mathrm{kg} \cdot \mathrm{m}^{-3}\right)$ of the solution. $K_{\mathrm{S}}$ decreases with increase in the concentration of Na-MCF and also with increase in temperature. The variation of $K_{\mathrm{S}}$ with molality is shown in the Figure 3 . The equation used for the determination of the apparent molar isentropic compressibility $\left(K_{\phi, \mathrm{S}}\right) /$ $\left(\mathrm{m}^{3} \mathrm{~mol}^{-1} \mathrm{~Pa}^{-1}\right)$ was

$$
K_{\phi, \mathrm{S}}=\left(1 / m \rho_{\mathrm{o}}\right)\left(K_{\mathrm{S}}-K_{\text {Solvent }}\right)+K_{\mathrm{S}} V_{\phi, \mathrm{m}} \ldots \ldots \ldots . .4
$$

$K_{\text {solvent }}$ is the isentropic compressibility of water. To calculate the limiting molar isentropic compressibility $\left(K_{\phi, \mathrm{S}}^{0}\right) /\left(\mathrm{m}^{3} \mathrm{~mol}^{-1} \mathrm{~Pa}^{-1}\right)$ the $K_{\phi, \mathrm{S}}$ data were fitted with the equation.

$$
K_{\phi, \mathrm{S}}=K_{\phi, \mathrm{S}}^{0}+a m^{0.5} \ldots \ldots \ldots \ldots \ldots \ldots \ldots \ldots \ldots \ldots \ldots \ldots \ldots \ldots \ldots \ldots \ldots \ldots
$$

Figure 4 presents the variation of $K_{\phi, S}$ with square root of molality. At $(298.15,303.15$, 308.15 , and 313.15$)$, the observed values of $K_{\phi, S}^{0}$ are $-3.39 \times 10^{-14},-2.28 \times 10^{-14},-1.14 \times$ $10^{-14}$ and $-0.145 \times 10^{-14}$, respectively. The values of $K_{\phi, S}^{0}$ were calculated by using least squares method. The negative values of $K_{\phi, S}^{0}$ are due to the strong Na-MCF-Water interaction. $K_{\phi, S}^{0}$ increases with increase in the temperature. The increase in the $K_{\phi, S}^{0}$ with temperature suggests that some water molecule will release in the bulk water. Na-MCF drug is electrolyte and therefore interact with the water by ion-dipole interactions which could lead to hydrophilic hydration around the anionic or cationic groups.

\begin{tabular}{|c|c|c|c|c|c|c|}
\hline $\begin{array}{c}m \\
\text { mol. } \mathrm{kg}^{-1} \\
\end{array}$ & $\begin{array}{c}u \\
\mathbf{m} \cdot \mathbf{s}^{-1}\end{array}$ & $\begin{array}{c}K_{S^{\times 10^{10}}} \\
\mathrm{~Pa}^{-1} \\
\end{array}$ & $\begin{array}{c}K_{\phi, \mathrm{S}^{\times}} \times 10^{14} \\
\mathrm{~m}^{3} \cdot \mathrm{mol}^{-1} \cdot \mathrm{Pa}^{-1} \\
\end{array}$ & $\begin{array}{c}u \\
\mathbf{m} \cdot \mathbf{s}^{-1}\end{array}$ & $\begin{array}{c}K_{S} \times 10^{10} \\
\mathrm{~Pa}^{-1} \\
\end{array}$ & $\begin{array}{c}K_{\phi, \mathbf{S}^{\times}} \times 10^{15} \\
\mathbf{m}^{3} \cdot \mathbf{m o l}^{-1} \cdot \mathbf{P a}^{-1} \\
\end{array}$ \\
\hline \multicolumn{4}{|c|}{ 298.15K } & \multicolumn{3}{|c|}{$303.15 \mathrm{~K}$} \\
\hline 0.000 & 1496.8 & 4.48 & $\begin{array}{c}K_{\phi, \mathrm{S}}^{0}=-3.39 \times 10^{-14} \\
\left(\mathrm{~m}^{3} \cdot \mathrm{mol}^{-1} \cdot \mathrm{Pa}^{-1}\right)\end{array}$ & 1509.0 & 4.41 & $\begin{array}{c}K_{\phi, S}^{0}=-2.28 \times 10^{-14} \\
\left(\mathrm{~m}^{3} \cdot \mathrm{mol}^{-1} \cdot \mathrm{Pa}^{-1}\right)\end{array}$ \\
\hline 0.1144 & 1508.8 & 4.35 & -1.70 & 1519.6 & 4.30 & -8.57 \\
\hline 0.1596 & 1512.4 & 4.31 & -1.35 & 1522.6 & 4.26 & -5.23 \\
\hline 0.2047 & 1515.6 & 4.27 & -1.08 & 1525.6 & 4.22 & -3.72 \\
\hline 0.2684 & 1519.4 & 4.22 & -0.77 & 1528.8 & 4.18 & -0.64 \\
\hline 0.3305 & 1522.8 & 4.18 & -0.50 & 1531.6 & 4.14 & 1.79 \\
\hline \multicolumn{4}{|c|}{$308.15 K$} & \multicolumn{3}{|c|}{$313.15 \mathrm{~K}$} \\
\hline 0.000 & 1519.0 & 4.36 & $\begin{array}{c}K_{\phi, S}^{0}=-1.14 \times 10^{-14} \\
\left(\mathrm{~m}^{3} \cdot \mathrm{mol}^{-1} \cdot \mathrm{Pa}^{-1}\right)\end{array}$ & 1528.0 & 4.32 & $\begin{array}{c}K_{\phi, \mathrm{S}}^{0}=-1.45 \times 10^{-15} \\
\left(\mathrm{~m}^{3} \cdot \mathrm{mol}^{-1} \cdot \mathrm{Pa}^{-1}\right)\end{array}$ \\
\hline 0.1144 & 1528.4 & 4.25 & -15.3 & 1536.4 & 4.22 & 5.87 \\
\hline 0.1596 & 1531.4 & 4.22 & 0.04 & 1539.0 & 4.19 & 7.09 \\
\hline 0.2047 & 1534.2 & 4.18 & 16.3 & 1541.2 & 4.16 & 8.52 \\
\hline 0.2684 & 1537.6 & 4.14 & 36.3 & 1544.4 & 4.11 & 9.61 \\
\hline 0.3305 & 1540.4 & 4.10 & 54.9 & 1546.8 & 4.07 & 11.0 \\
\hline
\end{tabular}

Table 2. Ultrasonic velocities $(\boldsymbol{u})$, isentropic compressibilities $\left(\boldsymbol{K}_{\mathbf{S}}\right)$, apparent molar isentropic compressibilities $\left(\boldsymbol{K}_{\phi, \mathbf{S}}\right)$, and limiting molar isentropic compressibilities $\left(\boldsymbol{K}_{\phi, \mathbf{S}}^{0}\right)$ of Na-MCF in Water. 


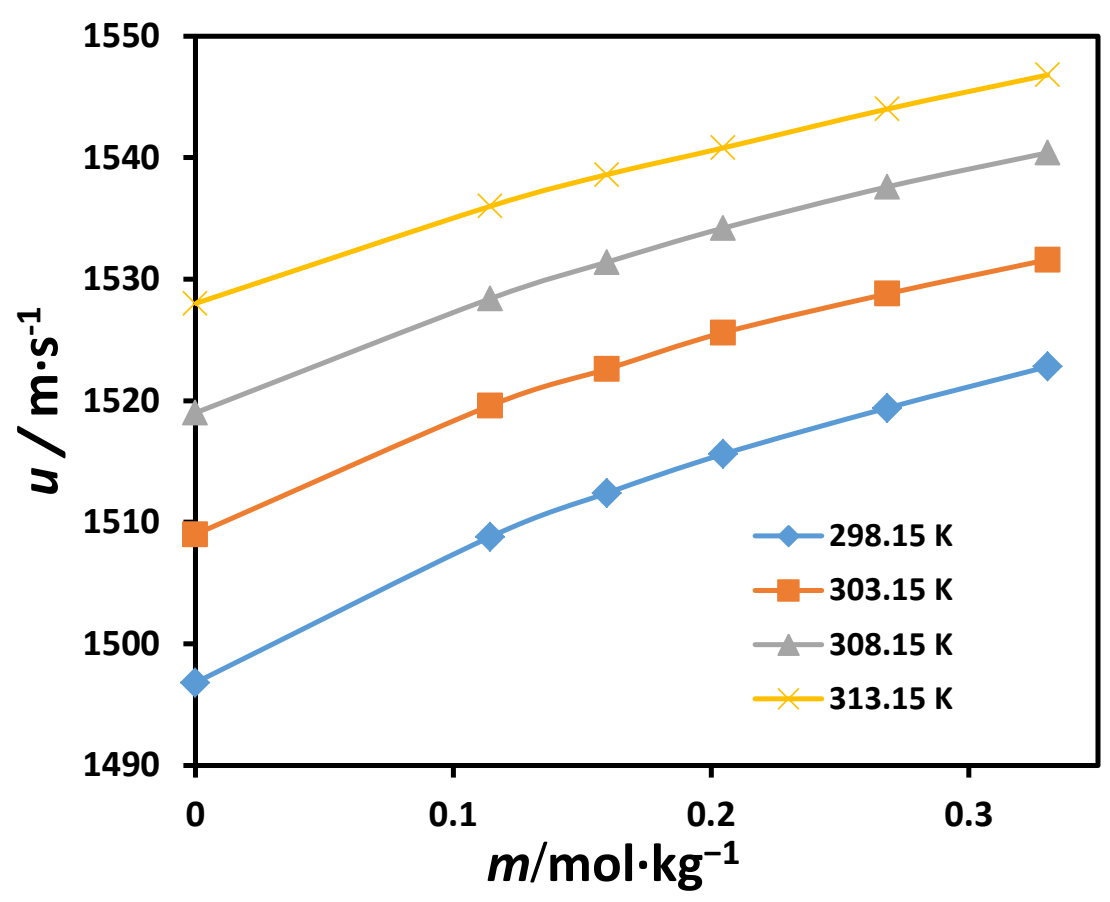

Figure 2. Variation of ultrasonic velocity of aqueous solutions of Na-MCF with molality.

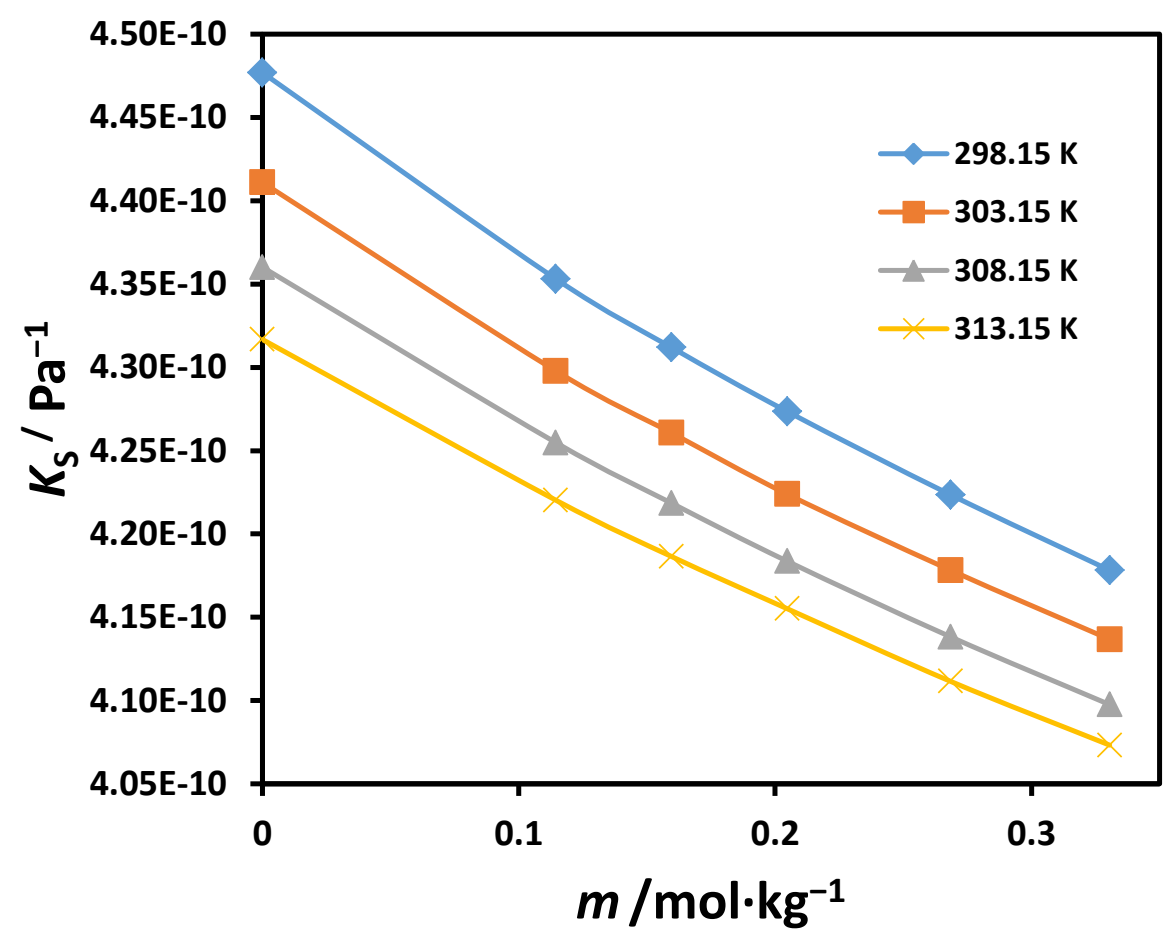

Figure 3. Variation of isentropic compressibility of aqueous solutions of Na-MCF with molality. 


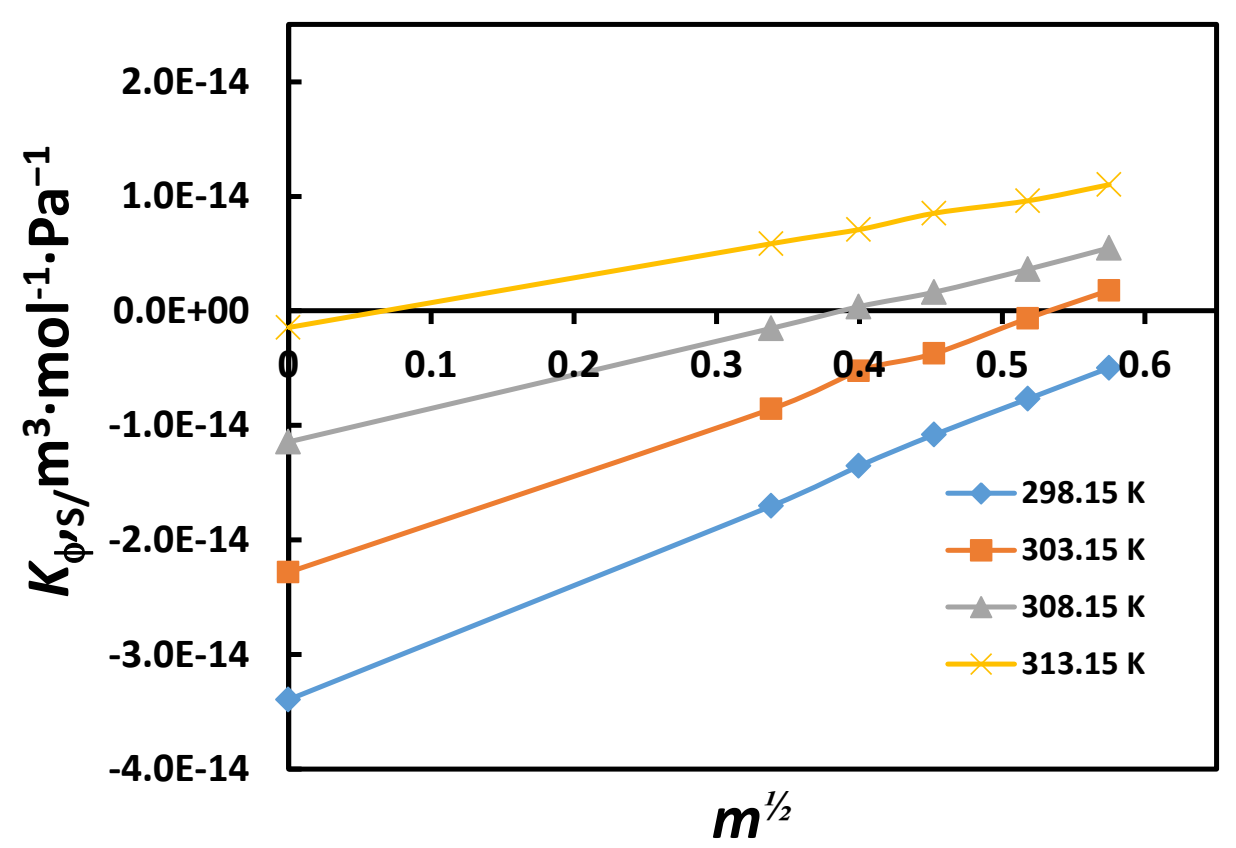

Figure 4. Variation of apparent molar isentropic compressibility of aqueous solutions of Na-MCF with square root of molality.

\section{3. Refractive indices}

Refractive indices of aqueous solutions of Na-MCF are reported in the Table 1. Refractive index varies linearly with molality of the Na-MCF aqueous solution. Figure 3 depicts the variation of refractive index with molality at different temperatures. Refractive index of aqueous solutions of $\mathrm{Na}-\mathrm{MCF}$ decreases with increase in the temperature.

\section{4. Computational study}

For calculation of hydration free energy $\left(\Delta G^{0}{ }_{\text {Hyd }}\right)$, geometry of Na-MCF was fully optimized using DFT RB3LYP method at $6-31++\mathrm{G}(\mathrm{d}, \mathrm{P})$ basis set. Hydration free energy $\left(\Delta G_{\text {Hyd }}^{0}\right.$ ), the work required to transfer a molecule from gas phase into the solution phase is calculated by the use of the equation

$$
\Delta G_{\mathrm{Hyd}}^{0}=\Delta G_{\mathrm{s}}^{0}-\Delta G_{\mathrm{g}}^{0}
$$

$\Delta G_{\mathrm{g}}^{0}$ and $\Delta G_{\mathrm{s}}^{0}$ represent standard free energy of solute in the gas phase and in solvent, respectively. The Integral Equation Formalism Polarizable Continuum (IEFPCM) solvation model was used to calculate $\Delta G^{0}{ }_{\text {Hyd }}$ with the help Gaussian G09W software [14].

The computed values of dipole moment of Na-MCF in gas phase and water are 6.21D and 6.97D, respectively. The increase in the dipole moment of Na-MCF suggests the increase in the ionic radius of Na-MCF while transforming from gas phase to water.

The computed values of free energies of Na-MCF in gas phase and water are 1827.5418 Hartee and -1827.5889 Hartee, respectively. Therefore, value of $\Delta G^{0}{ }_{\text {Hyd }}$ will be $29.54 \mathrm{kcal} \mathrm{mol}^{-1}$. The computed negative value of $\Delta G^{0}{ }_{\text {Hyd }}$ indicates strong Na-MCF-Water interaction. 
The computed HOMO and LUMO energies of Na-MCF are -0.1907 and -0.0592 Hartee, respectively. Therefore, the LUMO-HOMO energy gap will be -0.1315 Hartee. Small value of LUMO-HOMO energy gap indicates that Na-MCF is reactive.

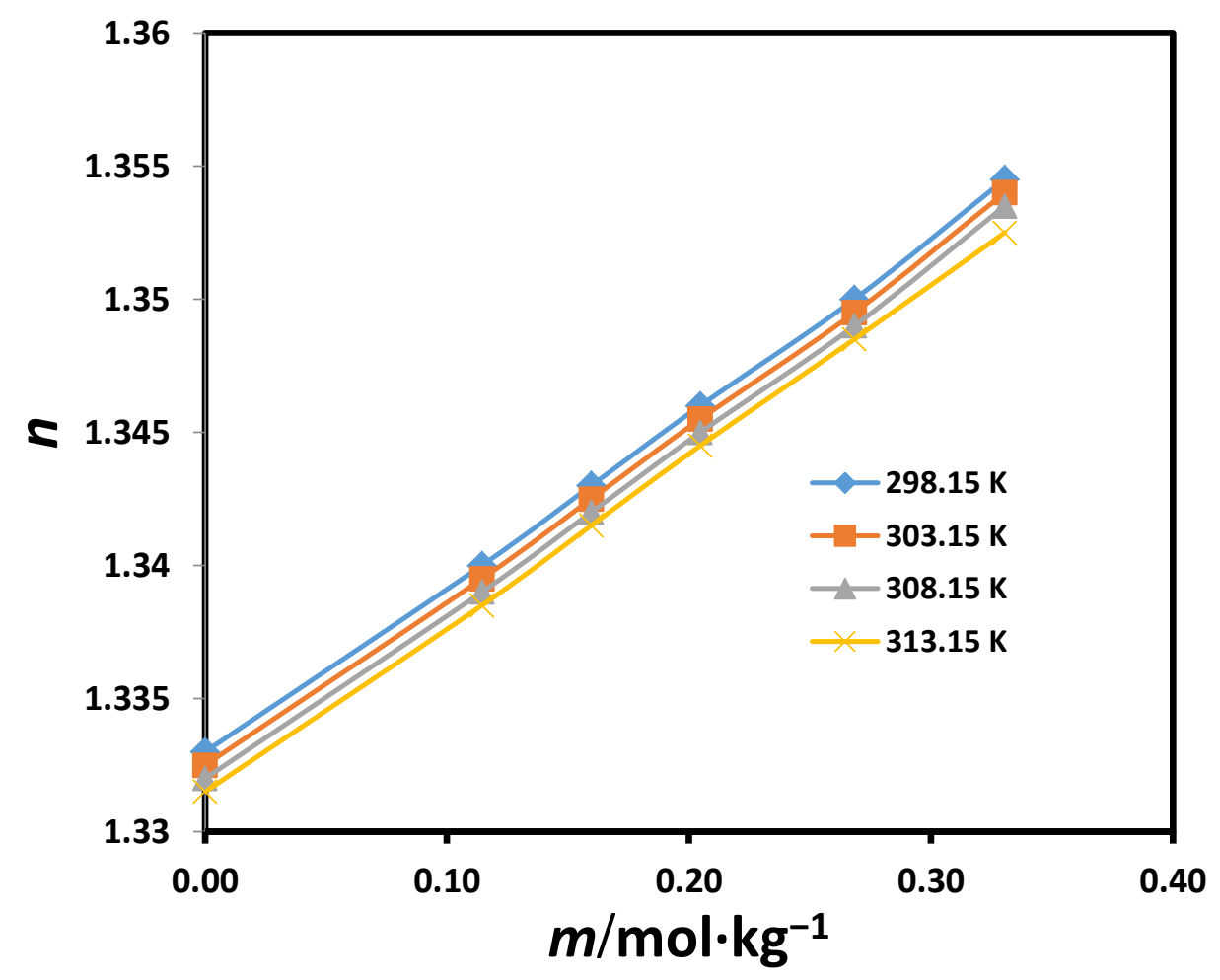

Figure 5. Variation of refractive index of aqueous solutions of Na-MCF with molality.

\section{CONCLUSION}

Positive values of limiting molar volumes suggest strong Na-MCF-water interactions. Isentropic compressibility decreases with increase in the concentration of Na-MCF and also with temperature. It is the indication of release of some water molecules into the bulk water. Limiting molar isentropic compressibility is negative.

The negative value suggests strong Na-MCF-water interactions. The type of interaction is ion-dipole interaction because Na-MCF is an electrolyte. The computed value of dipole moment of Na-MCF in water phase is greater than those of in gas phase.

This clarifies that the ionic radius of Na-MCF increases while transforming from gas phase to water. Negative hydration free energy of Na-MCF suggests strong Na-MCF-water interactions. Na-MCF is reactive because LUMO-HOMO energy gap is very small (negative).

\section{Acknowledgement}

This work has been performed under the Research Award Scheme of UGC (No. F.30-15/2011, SA-II), New Delhi, India. 


\section{References}

[1] S. J. Kharat, Thermochimica Acta 566 (2013) 124-129.

[2] S. J. Kharat, Physics and Chemistry of Liquids 52 (2014) 7-16.

[3] S. J. Kharat, International Journal of Thermophysics 31 (2010) 585-594.

[4] R.G. Parr and W. Yang, Density Functional Theory of Atoms and Molecules (Oxford) University Press, London, 1989.

[5] A.D. Becke, J. Chem. Phys. 98 (1993) 5648-5652.

[6] E. Cances, B. Mennucci, J. Tomasi, J. Chem. Phys. 107 (1997) 3032-3241.

[7] E. Cances and B. Mennucci, J. Math. Chem. 23 (1998) 309-326.

[8] D. Masson, Phil. Mag. 8 (1929) 218-223.

[9] A.F. Scott, J. Phys. Chem. 35 (1931) 2315-2329.

[10] W. Geffcken, Zeit. Phys.Chem. A155 (1931) 1-28.

[11] H.S. Harned, B.B. Owen, The Physical Chemistry of Electrolytic Solutions, 3rd ed., ACS Monograph No. 137, Reinhold Publishing Corp, New York, 1958.

[12] D.W. Kupke, Physical Principles and Techniques of Physical Chemistry, Part C Academic Press, New York, 1973.

[13] H.S. Harned, B.B. Owned, Physical Chemistry of Electrolyte Solutions, Chapman and Hall, London, 1957.

[14] Gaussian 09, Revision C.01, M.J. Frisch, G.W. Trucks, H.B. Schlegel, G.E. Scuseria, M.A. Robb, J.R. Cheeseman, G. Scalmani, V. Barone, B. Mennucci, G.A. Petersson, H. Nakatsuji, M. Caricato, X. Li, H.P. Hratchian, A.F. Izmaylov, J. Bloino, G. Zheng, J.L. Sonnenberg, M. Hada, M. Ehara, K. Toyota, R. Fukuda, J. Hasegawa, M. Ishida, T. Nakajima, Y. Honda, O. Kitao, H. Nakai, T. Vreven, J.A. Montgomery, Jr., J.E. Peralta, F. Ogliaro, M. Bearpark, J.J. Heyd, E. Brothers, K.N. Kudin, V.N. Staroverov, T. Keith, R. Kobayashi, J. Normand, K. Raghavachari, A. Rendell, J.C. Burant, S.S. Iyengar, J. Tomasi, M. Cossi, N. Rega, J.M. Millam, M. Klene, J.E. Knox, J.B. Cross, V. Bakken, C. Adamo, J. Jaramillo, R. Gomperts, R.E. Stratmann, O. Yazyev, A.J. Austin, R. Cammi, C. Pomelli, J.W. Ochterski, R.L. Martin, K. Morokuma, V.G. Zakrzewski, G.A. Voth, P. Salvador, J.J. Dannenberg, S. Dapprich, A.D. Daniels, O. Farkas, J.B. Foresman, J.V. Ortiz, J. Cioslowski, and D.J. Fox, Gaussian, Inc.,Wallingford, CT, 2010 . 